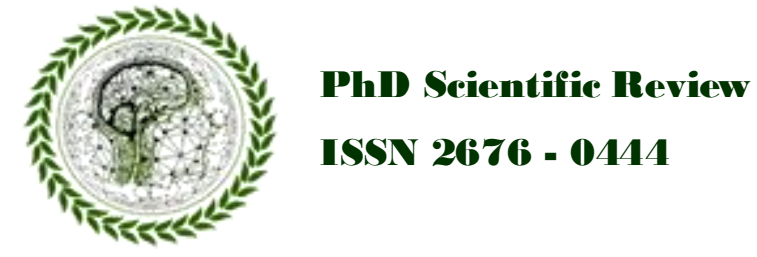

Artigo submetido em: 15/06/2021

Artigo aceito em: 16/06/2021

Artigo publicado em: 18/06/2021

\title{
GESTÃO PÚBLICA E SUSTENTABILIDADE
}

\author{
Dênis Fabrício Fernandes ${ }^{1}$
}

\section{RESUMO}

O presente estudo tem como objetivo abordar sinteticamente acerca das políticas públicas educacionais e o desenvolvimento sustentável, de modo a refletir sobre a relevância de se estudar e de se conscientizar sobre o desenvolvimento sustentável. No decorrer da leitura desta pesquisa ficará evidente que é preciso que o tema "Desenvolvimento Sustentável" esteja presente nos currículos escolares e universitários de todo o país. Para tanto, utilizar-se-á como base teórica autores como: Oliveira (2010), Azevedo (2003), Fien (1999), Souza (2003), entre outros. Em termos genéricos, o objetivo desta pesquisa será de investigar o que professores, especialistas e estudiosos dizem sobre o assunto, bem como salientar sobre a política pública educacional atual voltada para o desenvolvimento sustentável.

Palavras-chave: Políticas Públicas; Educacionais; Desenvolvimento; Sustentável.

\begin{abstract}
This study aims to synthetically address educational public policies and sustainable development, in order to reflect on the relevance of studying and raising awareness about sustainable development. In the course of reading this research, it will become evident that the theme "Sustainable Development" needs to be present in school and university curricula across the country. For this purpose, authors such as Oliveira (2010), Azevedo (2003), Fien (1999), Souza (2003), among others, will be used as a theoretical basis. In general terms, the objective of this research will be to investigate what teachers, specialists and scholars say about the subject, as well as to highlight the current educational public policy aimed at sustainable development.
\end{abstract}

Keywords: Public Policy; Educational; Development; Sustainable.

\footnotetext{
${ }^{1}$ Bacharel em Direito pela UTP e com especializações em: Direitos Humanos e Ressocialização pela Faculdade Única de Ipatinga; Gestão Pública pela Faculdade de Educação São Luís; Gestão de Segurança Pública pelo Centro Universitário Leonardo da Vinci; e Direito da Criança, do Adolescente e do Idoso pela Faculdade Única de Ipatinga. E-mail: fabriciocanova@gmail.com.
} 


\section{Introdução}

O objetivo deste artigo será de abordar acerca das políticas públicas educacionais e o desenvolvimento sustentável, de modo a refletir sobre a relevância e conscientização sobre o desenvolvimento sustentável, investigar o que professores e estudiosos dizem sobre o assunto, bem como salientar sobre a atual política pública educacional voltada para o desenvolvimento sustentável.

Sendo assim, para a elaboração deste artigo foi realizada a pesquisa bibliográfica qualitativa, através de autores como: Oliveira (2010), Pien (1999), Setubal (2012), Souza (2003), Rodrigues (2010), entre outros, além da base legal que trata sobre o assunto, pelos quais serão trazidos assuntos que envolvem a conceituação e contextualização de Políticas Públicas Educacionais, além de uma pincelada sobre a educação para o desenvolvimento sustentável.

\section{Contextualização de políticas públicas educacionais}

São direitos so ciais a educação, a saúde, a alimentação, o trab alho, a moradia, o lazer, a segurança, a previdên cia social, a proteção maternidade e à infân cia, a assistên cia aos desamparados, na fo rma desta Constituição (BRASIL, 1988, grifo nosso).

As Políticas Públicas englobam todos os grupos de necessidades da sociedade civil, que são as Políticas Sociais, estas determinam o padrão de proteção social implementado pelo Estado, voltadas em princípio, à redistribuição dos beneficios sociais (INEP, 2006, p. 165), dentre eles o direito a educação. Sendo assim, para que este direito seja garantido com qualidade e para todos é implementada a Política Pública Educacional, conforme será visto a seguir.

\subsection{Definição de políticas públicas}

O Novo Dicionário Aurélio da Língua Portuguesa (1986) conceitua a palavra política como: "ciência dos fenômenos referentes ao Estado; ciência política (...). Conjunto de objetivos que informam determinado programa de ação governamental e condicionam a sua execução (...)”. (FERREIRA, 1986, p. 1358). 
Quanto à definição de público, entende-se como “do, ou relativo, ou pertencente ou destinado ao povo, à coletividade (...), ou, ainda, (...) relativo ou pertencente a o governo de um país (...)”. (FERREIRA, 1986, p. 1414).

Diante desses dois conceitos, apesar de superficiais, já é possível compreender um pouco melhor o que seria de fato a política pública educacional, e assim defini-la como uma ação ou omissão governamental condicionada a uma execução destinada à coletividade.

Políticas públicas são ações de governo, as quais são revestidas da autoridade soberana do poder público. Dispõem sobre “o que fazer", "aonde chegar” e "como fazer". (RODRIGUES, 2010, p. 52-53).

Diversos outros autores definem políticas públicas de várias maneiras, porém com semelhanças conceituais quantos aos efeitos das ações governamentais na vida das pessoas. Mead (1995) entende que políticas públicas seria um "campo dentro do estudo da política que analisa o governo à luz de grandes questões públicas”. Lynn (1980) define que seria "um conjunto específico de ações do governo que irão produzir efeitos específicos". Já Peters (1986), vê como uma "soma das atividades dos governos, que agem diretamente ou através de delegação, e que influenciam a vidas dos cidadãos". (MEAD, 1995; LYNN, 1980; PETERS, 1986 a pud OLIVEIRA, 2010).

$\mathrm{Na}$ concepção de Azevedo (2003, p. 38) “política pública é tudo o que um governo faz e deixa de fazer, com todos os impactos de suas ações e de suas omissões".

Sob esse entendimento, compreende-se que:

\begin{abstract}
Se "políticas públicas" é tudo aquilo que um governo faz ou deixa de fazer, políticas públicas educacionais é tudo aquilo que um governo faz ou deixa de fazer em educação. Porém, educa ção é um conceito muito amplo para se tratar das políticas educacionais. Is so quer dizer que políticas educacionais é um foco mais específico do tratam ento da educação, que em geral se aplica às questões escolares. Em outras palavras, pode-se dizer que políticas públicas educacionais dizem respeito à edu cação es colar. (OLIVEIRA, 2010, p. 96).
\end{abstract}

De acordo com Souza (2003), políticas públicas é um campo do conhecimento que tem como foco, tanto "colocar o governo em ação" e/ou analisar essa ação (variável independente) como propor mudanças no rumo ou curso dessas ações e ou entender por que o como as ações tomaram certo rumo em lugar de outro (variável dependente). Ou seja, o processo de formulação de política pública é aquele através do qual os governos traduzem suas intenções em programas e 
ações, que produzirão efeitos, consequências ou as mudanças desejadas na vida das pessoas (SOUZA, 2003, p. 13).

Percebe-se, que a educação é um direito imprescindível e universal, e cabe ao governo do país criar e executar políticas públicas capazes de garantir sua qualidade social, bem como o acesso e permanência de todos. Ressalta-se que o Estado e o principal construtor de espaços de participação direta, indireta e representativa, nos quais a sociedade civil possa atuar concretamente na gestão e execução dessas políticas públicas educacionais.

Portanto, a autora Rodrigues (2010, p. 53) esclarece que Políticas públicas resultam das atividades políticas, englobam mais de uma decisão política e necessitam de várias ações estratégicas voltadas a implementar objetivos desejados. Exercem um conjunto articulado de ações, decisões e incentivos que buscam alterar uma realidade em resposta a demandas e interesses envolvidos.

\section{Conceitualização de desenvolvimento sustentável e ecodesenvolvimento}

Para não deixar lacunas de compreensão acerca do tema aqui proposto, faz-se relevante descrever o conceitualização atual de desenvolvimento sustentável e a diferença entre Ecodesenvolvimento e Desenvolvimento Sustentável, com o escopo de propiciar um melhor entendimento sobre o assunto, não obstante vários autores tratarem esses dois termos como sinônimos.

De acordo com Layrargues (1997):

[...] enquanto o ecodesenvolvimento postula com relação à justiça social, que seria necessário estabelecer um teto de consumo, com um nivelamento médio entre o primeiro e terceiro mundo, o desenvolvimento sustentável afirma que seria necessário estabelecer um piso de consumo, omitindo o peso da responsabilidade da poluição da riqueza. Enquanto o ecodes envolvimento reforça o perigo da crença ilimitada na tecnologia moderna, e prioriza a criação de tecnologias endógenas, o desenvolvimento sustentável continua acreditando firmemente no potencial da tecnologia moderna, e ainda propõe a transferência de tecnologia como o critério de "ajuda" ao terceiro mundo. Enquanto o ecodes envolvimento coloca limites à livre atuação do mercado, o desenvolvimento sustentável afirma que a solução da crise ambiental virá com a instalação do mercado total na economia das sociedades modernas. (LAYRARGUES, 1997, p. 6).

Na visão de Romeiro (2003, p. 5-6), o desenvolvimento sustentável é uma definição normativo que teve a sua origem a partir do termo "ecodesenvolvimento", a fim de ajustar o 
desenvolvimento sócio-econômico, em termos atuais, com a sustentabilidade. Ou seja, o conceito de ecodesenvolvimento emerge desse contexto como uma proposição conciliadora, onde se reconhece que o progresso técnico efetivamente relativiza os limites ambientais, embora não os elimine, e que o crescimento econômico é condição necessária, mas não suficiente, para a eliminação da pobreza e das disparidades sociais (ROMEIRO, 1999, p. 76-77).

No entendimento de Maimon (1992), a diferença principal entre Ecodesenvolvimento e Desenvolvimento Sustentável reside em: aquele se volta ao atendimento das necessidades básicas da população, através de tecnologias apropriadas a cada ambiente, partindo do mais simples ao mais intricado; enquanto este explora uma política ambiental, a responsabilidade com gerações futuras e a responsabilidade comum com os problemas generalizados. (MAIMON, 1992).

De acordo com Montibeller (2004), a expressão desenvolvimento sustentável, de origem anglo-saxônica (sustainable development), é difundida a partir dos anos 80, como um novo paradigma sobre a conservação e o desenvolvimento, apresentando como princípios: integrar conservação da natureza e desenvolvimento; satisfazer as necessidades humanas fundamentais; perseguir a equidade e a justiça social; buscar a autodeterminação social e respeitar a diversidade cultural; e manter a integridade ecológica. (MONTIBELLER, 2004, p. 49-50).

Fernandes (2000) afirma que o termo desenvolvimento sustentável foi utilizado pela exministra da Noruega, Gro Harlem Brundtland, no ano de 1987, e pode ser conceituado como:

\footnotetext{
"Aquele que atende às necessidades do presente, sem comprometer a possibilidade de as geraçõ es futuras atenderem suas próprias necessidades, como também é uma forma de otimizar o uso racional dos recursos naturais e a garantia de cons ervação e do bem estar para as geraçõ es futuras “. (FERNANDES, 2000, p. 3).
}

Esse conceito é o mais aceito hoje em dia e surgiu na Comissão Mundial sobre Meio Ambiente e Desenvolvimento (1987), criada pelas Nações Unidas para discutir e propor meios de harmonizar dois objetivos: o desenvolvimento econômico; e a conservação ambiental.

Segundo Padilha (2010), destaca-se que em 1987, após diveros estudos sobre o assunto, a Comissão Mundial da ONU sobre o Meio Ambiente e Desenvolvimento (CMMAD), publicou o estudo cujo tema: "Nosso Futuro Comum", nominado como Relatório Brundtand, dentre outros problemas, salientando a pobreza de muitos como sendo um dano ambiental crescente e a obrigação de criação de outro sistema econômico, ou seja, um desenvolvimento sustentável que não viesse a maleficiar as futuras gerações. (PADILHA, 2010, p. 244). E ainda acrescenta: 


\begin{abstract}
“[...] enquanto um programa global para programar o processo de implantação de um modelo de desenvolvimento econômico respeite os prinápios da sustentabilidade ambiental e que, por si só, já é uma confirmação senão por um longo e árduo processo de transição. E, embora se constitua em um documento multilateral, juridicamente não obrigatório, possui grande impacto nas políticas públicas internas. Nesse sentido, a Agenda 21 Brasileira define ações prioritárias e estratégias do pacto social brasileiro para a conquista do desenvolvimento sustentável, buscando influenciar políticas públicas e o setor privado, no sentido de firmar as bases para a sustentabilidade do processo de desenvolvimento nacional". (PADILHA, 2010, p. 247-248).
\end{abstract}

\title{
4 Políticas públicas educacionais
}

Nas primeiras seções deste artigo foram trabalhados de forma sumária os conceitos de políticas públicas. Já a partir daqui será observado o que de fato significam as políticas públicas educacionais e as suas dinâmicas influenciam na sua decisão.

A principal fonte de implementação da educação nacional e das políticas que assim as definem é a Lei de Diretrizes e Bases da Educação Nacional (LDB), que com o passar dos anos foram se adequando até o sistema atual datado de 1996, que sofreram alterações de acordo com os governos.

Ressalta-se que no Brasil, especialmente nos últimos dez anos, o termo Políticas Públicas ganhou um rol de notoriedade em todos os campos. Fala-se de Políticas Públicas para a educação, cultura, saúde, justiça, esporte e assistência social. Contudo, essas políticas nem sempre trazem os resultados esperados, já que somente garantir o acesso a todos estes serviços públicos não significa, necessariamente, que estes tenham qualidade e que os usuários terão seus direitos respeitados. (SETUBAL, 2012).

Sabe-se que é importante valorizar o cidadão como protagonista consumidor dos serviços públicos e adotar pesquisas de satisfação de usuários como parâmetros para avaliação de desempenho no setor público. Assim o cidadão torna-se cliente e consumidor dos serviços prestados pelo Estado. (PIMENTA, 1998, p. 183).

Ao analisar as políticas públicas e tendo como base a educação, deve-se ter como fundamento que as políticas públicas educacionais são aquelas que regulam e orientamos sistemas de ensino, instituindo a educação escolar. Essa educação escolar moderna desenvolveu-se a partir dos meados do século XIX e acompanhou o desenvolvimento do próprio capitalismo, e chegou à era da globalização resguardando um caráter mais reprodutivo, tendo em vista a redução de recursos investidos nesse sistema que de forma pré-disponível acontece nos países que implantam os ajustes neoliberais. (OLIVEIRA, 2010, p. 99). 
Sendo assim, ao se falar em Políticas Públicas na educação a abordagem trata-se da articulação de projetos que envolvem o governo e a sociedade, na busca pela construção de uma educação que resgate a construção da cidadania. (GIRON, 2008, p. 47).

O Plano Nacional de Educação é a principal política pública positivada e tem como alvo a melhoria da educação. Vem amparado na Constituição Federal (CF) e objetiva efetivar os deveres do Estado em relação à Educação. Dessa forma, ao analisar os Artigos 208 e 214 da Constituição Federal, pode-se extrair a razão política dos Planos de Educação. Segundo a CF:

Art. 208. O dever do Estado com a educação será efetivado mediante a garantia de: I educação básica obrigatória e gratuita dos 4 (quatro) aos 17 (dez essete) anos de idade, assegurada indusive sua oferta gratuita para todos os que a ela não tiveram acesso na idade própria;

II - progressiva universalização do ensino médio gratuito;

III - atendimento educacional especializado aos portadores de deficiência, preferencialmente na rede regular de ensino;

IV - edu cação infantil, em crech e e pré-escola, às crianças até 5 (cin co) anos de idade; $\mathrm{V}$ - acesso aos níveis mais elevados do ensino, da pesquisa e da criação artística, segundo a capacidade de cada um;

VI - oferta de ensino noturno regular, adequado às condiçõ es do edu cando;

VII - atendimento ao educando, em todas as etapas da educação básica, por meio de programas suplementares de material didático-escolar, transporte, alimentação e assistên dia à s aúde. (BRASIL, 1988).

Já no artigo 214 da Constituição Federal, tem-se:

Art. 214. A lei estabelecerá o plano nacional de educação, de Duração decenal, com o objetivo de articular o sistema nacional de Educação em regime de colaboração e definir diretrizes, objetivos, metas e estratégias de implementação para assegurar a manutenção e desenvolvimento do ensino em seus diversos níveis, etapas e modalidades por meio de ações integrad as dos poderes públicos das diferentes esferas federativas que conduzam a:

I - erradicação do an alfab etismo;

II - universalização do atendimento es colar;

III - melhoria da qualidade do ensino;

IV - formação para o trabalho;

V - promoção humanística, científica e tecnológica do País.

VI - estabelecimento de meta de aplicação de recursos públicos em educação como proporção do produto interno bruto. (BRASIL, 1988).

Portanto, resta evidente que a judicialização da educação deve ser vista como uma exceção. Exige-se que todos os envolvidos nas políticas públicas garantam a sua efetividade e qualidade sem a necessidade de pedir ajuda ao judiciário. Devem-se especialmente entrar em 
ação: "a escola, os professores, os conselhos de escola, gestores, sindicatos, universidade, os pais e responsáveis, Ministério Público, etc.” (FERREIRA; NOGUEIRA, 2015, p. 21-22).

$\mathrm{Na}$ visão de Ferreira e Nogueira (2015, p. 22), o Ministério Público deve assumir o papel principal de ações que busquem a efetivação dos planos, com a fiscalização dos prazos previstos, das metas, estratégias e dos direitos assegurados. Ao perceber as falhas, a negociação articulada e/ou indução para a efetivação de política pública específica deve ser o caminho a seguir. O objetivo é o direito à educação de forma democrática para a coletividade. Neste particular, destaca-se a importância da visão global do direito e não apenas o direito individual. A educação busca a igualdade entre as pessoas, para que este direito seja garantido a todos indistintamente.

\section{A educação e o desenvolvimento sustentável}

Conforme já foi visto anteriormente, o desenvolvimento sustentável foi apoiado pela primeira vez durante a Assembleia Geral das Nações Unidas no ano de 1987, assim como foi explorada a discussão a respeito do desenvolvimento sustentável. A Conferência das Nações Unidas para o Meio Ambiente e o Desenvolvimento no Rio de Janeiro (Rio-92) uniu representantes de governos, organizações internacionais e não-governamentais e sociedade civil para colocar em pauta os desafios do próximo século e adotar um plano global de ação para enfrentá-los. O plano de ação forneceu uma série de princípios para auxiliar os Governos e outras instituições na implementação de políticas e programas para o desenvolvimento sustentável.

Segundo o capítulo 36 da Agenda $2^{2}$ (Plano de Ação), a educação é essencial no rumo ao desenvolvimento sustentável:

\footnotetext{
O ensino, inclusive o ensino formal, a consciência pública e o treinamento devem ser reconhecidos como um processo pelo qual. os seres humanos e as sociedades podem desenvolver plenamente suas potencialidades. $O$ ensino tem fundamental importância na promoção do desenvolvimento sustentável e para aumentar a capacidade do povo para abordar questões de meio ambiente e desenvolvimento. Ainda que o ensino básico sirva de fundamento para o ensino em matéria de ambiente e desenvolvimento, este último deve ser in corpo rado como parte essencial do aprendizado. Tanto o ensino formal como o informal são indispensáveis para modificar a atitude das pessoas, para que estas tenham
}

\footnotetext{
${ }^{2}$ A Agenda 21, o qual foi assinado por 178 países na Rio Eco 1992, funciona como um manual básico para a implementação do desenvolvimento sustentável.
} 
capacidade de avaliar os problemas do desenvolvimento sustentável e abordálos. O ensino é também fundamental para conferir consciência ambiental e ética, valores e atitudes, técnicas e comportamentos em consonância com o desenvolvimento sustentável e que favoreçam a participação pública efetiva nas tomadas de deci são [...]. (ONU, 1995, p. 429-430, grifo nosso).

Infelizmente, no Brasil o tema educar para sustentabilidade ainda é pouco conhecido no âmbito educacional do país, em se tratando de práticas concretas que relacionam a natureza e a educação.

A dimensão ambiental insere vários atores do universo educativo, tendo em vista que necessita de diversas áreas do conhecimento, a capacitação desses profissionais e de toda a comunidade preocupada com a construção do saber. Hoje em dia, a informação possui um papel cada vez mais importante seja através da mídia, dos jornais ou até mesmo da internet. Diante disso, a educação representa a "possibilidade" de motivar e sensibilizar as pessoas para transformar as diversas formas de participação na defesa da qualidade de vida. (JACOBI, 2003, p.190).

Jacobi (2003, p. 204) esclarece ainda que a sustentabilidade tem como alvo superar o reducionismo e incentivar um pensar e fazer sobre o meio ambiente que está relacionado ao diálogo entre saberes tal como a participação da comunidade, aos valores éticos, pois fortalece a ampla interação entre a sociedade e a natureza. A educação ambiental nos leva repensar nas práticas sociais e a função dos professores como mediadores do conhecimento, para que os alunos consigam uma base adequada de entendimento da natureza como um todo, das dificuldades e soluções relacionadas à mesma, e da responsabilidade de cada individuo para construir uma sociedade planetária mais consciente e ambientalmente sustentável.

O Capítulo 36, da Agenda 21 (1995, p. 429) expõe que para a educação ser voltada ao Desenvolvimento Sustentável, a mesma necessita ser ajustada em três grandes campos, os quais seriam: "reorientação do ensino no sentido do desenvolvimento sustentável; aumento da consciência pública; e promoção do treinamento.”

A questão é que não se pode esperar que o sistema de educação formal, que na verdade atinge crianças por apenas um período de suas vidas, ministre as pessoas tudo sobre como viver, trabalhar e governar para que alcancem a sustentabilidade em seu ambiente. Ditoso, a educação sozinha não carrega a responsabilidade da educação para o desenvolvimento sustentável. Os setores não formal e informal da educação devem trabalhar juntos para educar todas as pessoas, em todas as fases da vida (TILBURY et al., 2002, p. 13). 
Por isso, segundo Fien (1999, p. 89) há ao menos quatro princípios imprescindíveis que inclua a Educação para o Desenvolvimento Sustentável (EDS) em se tratando de um programa de formação de educadores ou professores. O primeiro princípio caracteriza-se pela conscientização de "todos os professores para as suas responsabilidades em educar os alunos para a participação na sociedade civil e na promoção do desenvolvimento sustentável”, sendo preciso propiciar-lhes chances para se familiarizarem "com os conceitos e processos da sustentabilidade" e com as habilidades e competências profissionais essenciais "para ensinar de forma efetiva a participação na sociedade civil.” (FIEN, 1999, p. 89).

Quanto ao segundo princípio, Fien (1999, p. 89), trata da reorientação dos programas de formação de professores que deverão passar a incorporar "estudos integrados e/ou disciplinares de filosofia, sociologia e psicologia da educação", assim como "metodologias de ensino, teoria curricular e estudos curriculares aplicados", que possibilitem reorientar o ensino de diferentes conteúdos numa perspectiva de EDS.

O terceiro princípio está especificamente voltado para os professores que se querem concentrar na educação ambiental, a quem deverá ser assegurada a possibilidade de adquirir competências nessa área, bem como "disciplinas especializadas em desenvolvimento sustentável e/ou estudos curriculares aplicados para diferentes conteúdos escolares.” (FIEN, 1999, p. 90).

E, finalmente, o quarto está voltado para as questões da formação continuada, no sentido de que ela deve ser adequada de forma que os professores "reflitam sobre os seus compromissos educativos e práticas pedagógicas em resposta às solicitações das turmas e desenvolver competências e planos para ensinar para um mundo sustentável.” (FIEN, 1999, p. 90).

De acordo com Freitas (2004, p. 560), os quatro princípios acima têm consequências diretas e indiretas na definição de intervenções de formação inicial e contínua, "podendo e devendo ser explicitados, clarificados e renunciados, por forma a tornar mais clara a natureza das mudanças que se pretendem introduzir".

Dessa maneira, percebe-se a importância de uma adequação nos currículos escolares no sentido de adotarem os conceitos de sustentabilidade nas escolas em todos os níveis educacionais. Segundo Weber (2014), a Organização das Nações Unidas para Educação, Ciência e Cultura (Unesco) quer que:

[...] a chamada edu cação para o des envolvimento sustentável faça parte da nova agenda de compromissos globais que será estabelecida pelas Nações Unidas no período de 2015 a 2030. Empenhados em traçar estratégias para que escolas de todo o planeta adotem conceitos de sustentabilidade em seus currículos, 1.100 representantes de 148 
países passaram os últimos três dias reunidos em Nagoia, no Japão. Eles con duíram que formar professores e mobilizar a juventude são ações urgentes. (WEBER, 2014, p. $\mathrm{s} / \mathrm{n})$.

Não sem tem dúvidas de que há um passo enorme a ser dado para que, de fato, a Educação para o Desenvolvimento Sustentável, ou, ainda a Educação Ambiental, esteja presente como tema transversal no currículo da escola. Em contrapartida, conforme Schuvartz (2013, p. 12), "pouco iremos avançar se não envolvermos as universidades na formação inicial e continuada de professores e educadores nos diversos espaços educativos."

No entanto, o que se percebe é que o principal mistério nos tempos modernos do desenvolvimento sustentável nos parece que se encontra entre a necessidade de permanecer ampliando e consagrando suas bases de sustentação político-social, com o intuito de transformarse numa possibilidade realista ao modelo de desenvolvimento dominante, e a exigência de fornecer uma forte base científica a suas políticas, a fim de que igualmente sejam realistas, ainda a risco de contradizer os pressupostos ideológicos de certos setores de sua base político-social. (VIOLA; LEIS, 1995, p. 79).

\section{Considerações finais}

É sabido que a Educação para o Desenvolvimento Sustentável é um desafio da política pública que implica em uma ação participativa tanto do governo como da sociedade. Infelizmente, no Brasil o tema educar para sustentabilidade ainda é pouco explorado em âmbito educacional, e em práticas concretas que relacionam a educação e a natureza.

O luta para implementar a Educação para o Desenvolvimento Sustentável requer parcerias entre instituições acadêmicas e científicas, professores, Organizações Governamentais e Não-Governamentais, comunidades locais, entre outros. A presente década disponibiliza uma oportunidade para reorientar a educação em direção à conscientização de que todos nós compartilhamos um destino comum e um compromisso de um futuro melhor para as pessoas e o planeta.

Espera-se, portanto, que a educação de fato torne-se uma ferramenta de apoio ao desenvolvimento sustentável, assim como seja um processo de democracia, capaz de fazer o alicerce da cidadania através do saber e da reflexão do ambiente (do mundo) em que estamos 
inseridos. É a estrada perfeita para a aquisição da exatidão social, política e econômica de uma sociedade comprometida com a harmonia e a preservação do Planeta Terra.

"Se a educação sozinha não transforma a sociedade, sem ela, tampouco, a sociedade muda." (Paulo Freire).

\section{REFERÊNCIAS BIBLIOGRÁFICAS:}

AGENDA 21. Conferência das Nações Unidas sobre o Meio Ambiente e Desenvolvimento. Câmara dos Deputados. Biblioteca Digital. 1995. Disponível em: <http://www.onu.org.br/rio20/img/2012/01/agenda21.pdf>. Acesso em: 10 mar. 2017.

AZEVEDO, Sérgio de. Políticas públicas: discutindo modelos e alguns problemas de implementação. In: SANTOS JÚNIOR, Orlando A. Dos (et. al.). Políticas públicas e gestão local: programa interdisciplinar de capacitação de conselheiros municipais. Rio de Janeiro: FASE, 2003.

BRASIL. Constituição Federal de 1988. Constituição da República Federativa do Brasil, promulgada em 5 de outubro de 1988. 24a. ed. São Paulo: Saraiva, 2000. (Coleção Saraiva de Legislação). Disponível em: < http://www.planalto.gov.br/ccivil_03/constituicao/constituicao.htm>. Acesso em: 1 jan. 2017.

Lei de Diretrizes e Bases da Educação Nacional. Lei no 9.394/96, de 20 de dezembro de 1996. Disponível em: <http://www.planalto.gov.br/ccivil_03/leis/L9394.htm>. Acesso em: 15 fev. 2017.

FERNANDES, J.W.N. A gestão ambiental e o desenvolvimento sustentável sob a ótica da contabilidade. IN: XVI Congresso Brasileiro De Contabilidade. 2000, Goiás. Conselho Federal de Contabilidade.

FERREIRA, Aurélio Buarque de Holanda. Novo dicionário da língua Portuguesa. $2^{a}$ edição. Revista e Ampliada. Rio de Janeiro: Nova Fronteira, 1986.

FERREIRA, Luiz Antonio Miguel; NOGUEIRA, Flávia Maria de Barros. Impactos das políticas educacionais no cotidiano das escolas públicas Plano nacional de educação. $2015 . \quad$ Disponível em: $<$ http://pne.mec.gov.br/images/pdf/Noticias/impactos_politicas_educacionais_cotidiano_escol as_publica_PNE.pdf $>$. Acesso em: 13 fev. 2017. 
FREITAS, Mário. A educação para o desenvolvimento sustentável e a formação de educadores/professores. Perspectiva, Florianópolis, v. 22, n. 02, p. 547-575, jul./dez. 2004. Disponível em: <file://C:/Users/D\%C3\%AAnis/Downloads/9666-28817-1-PB.pdf>. Acesso em: 8 mar. 2017.

GIRON, Graziela Rossetto. Políticas públicas, educação e neoliberalismo: o que isso tem a ver com a cidadania. Revista de Educação. PUC-Campinas. Campinas. n.24. jun. 2008.

INEP/MEC. Enciclopédia de pedagogia universitária: glossário vol. 2 / Editora-chefe: Marilia Costa Morosoni. - Brasília: Instituto Nacional de Estudos e Pesquisas Educacionais Anísio Teixeira, 2006.

JACOBI, P. Educação ambiental, cidadania e sustentabilidade. Cadernos de Pesquisa, São Paulo, n. 118, p. 189-205, março 2003.

LAYRARGUES, Philippe P. Do ecodesenvolvimento ao desenvolvimento sustentável: evolução de um conceito?, 1997. Disponível em: <http://material.nereainvestiga.org/publicacoes/user_35/FICH_ES_32.pdf>. Acesso em: 10 Jan. 2017.

MAIMON, Dália. Ensaios sobre Economia do Meio Ambiental. Rio de Janeiro: Aped Associação de Pesquisa e Ensino em Ecologia e Desenvolvimento, 1992.

MONTIBELLER, Gilberto Filho. O Mito do Desenvolvimento Sustentável. Editora da UFSC. Florianópolis, 2004.

OLIVEIRA, Adão F. de. Políticas públicas educacionais: conceito e contextualização numa perspectiva didática. (In: OLIVEIRA, A. F. de; PIZZIO, A.; FRANÇA, G. (Orgs). Fronteiras da Educação: desigualdades, tecnologias e políticas. Góias: Editora PUC, 2010).

PADILHA, Norma Sueli. Fundamentos Constitucionais do Direito Ambiental Brasileiro. Ed. Elsevier, 2010.

PIMENTA, C.C. A reforma gerencial do estado brasileiro no contexto das grandes tendências mundiais. In: Revista de Administração Pública, Rio de Janeiro, 32 (5), 1998.

RODRIGUES, Marta Maria Assumpção. Políticas Públicas. São Paulo: Publifolha, 2010. 
ROMEIRO, Ademar Ribeiro. Introdução: Economia ou Economia política da sustentabilidade. In: MAY, Peter H.; LUSTOSA, Maria Cecília; VINHA, Valéria da. Economia do meio ambiente: Teoria e pratica. 2. ed. Rio de Janeiro: Editora Campus, 2003.

Desenvolvimento sustentável e mudança institucional: notas preliminares. Vol. 1, Rio de Janeiro: Revista Econômica, 1999.

SETUBAL, Maria Alice. Com a palavra... Consulex. Ano XVI. n. 382. 15 de Dezembro de 2012.

SOUZA, Celina. Políticas públicas: questões temáticas e de pesquisa. Caderno CRH, Salvador, n. 39, jul./dez. 2003.

SHUVARTZ, Marilda. Educação, Trabalho de Desenvolvimento Sustentável. Texto 1: Educação e sustentabilidade: desafios e proposições à luz da Conae/2014 e do PNE. Salto Para o Futuro. Ano XXIII - Boletim 15 - Set.2013. Disponível em: $<$ http://cdnbi.tvescola.org.br/resources/VMSResources/contents/document/publicationsSeries /18350515_DesenvolvimentoSustentavel.pdf>. Acesso em: 7 jan. 2017.

TILBURY, D., STEVENSON, R. B., FIEN, J., SCHREUDER, D. Education for Sustainable Development: Dimensions of Work. IUCN Commission on Education and Communication The World Conservation Union. 2002.

WEBER, Demétrio. Unesco quer educação para o desenvolvimento sustentável no currículo das escolas. Site: O Globo, 2014. Disponível em: http://oglobo.globo.com/sociedade/educacao/unesco-quer-educacao-para-desenvolvimentosustentavel-no-curriculo-das-escolas-14546198. Acesso em: 4 jan. 2017. Sem paginação.

VIOLA, Eduardo J.; LEIS, Hector R. A Evolução das políticas ambientais no Brasil-1971-91: do bissetorialismo preservacionista para o multissetorialismo orientado para o desenvolvimento sustentável. In: HOGAN, Daniel J.; VIEIRA, Paulo F. (Org.). Dilemas Socioambientais e desenvolvimento Sustentável. 2. ed. Campinas:

Unicamp, 1995. 